\title{
City Sign Design and the Application of Cultural Elements
}

\author{
Xiao Xiao, You Lu, Zhi Wang, and Yanfang Liu
}

\begin{abstract}
City sign plays a positive role in the mold of the city image and the promotion of the city brand. It promotes the communication and transmission of the cities' economic culture. Typical cultural elements of city sign design can build the city image and outstand the features of city culture. They are the cities' typical visual identification symbols.
\end{abstract}

Index Terms-City sign design; cultural element; visual communication design; application.

\section{INTRODUCTION}

Every city in its development and construction process will form some personality features belong to itself. These unique features often represent the cultural characteristics of the city. Therefore, the contents which can express the city connotation will become the iconic cultural symbols of the city. As an important content of external publicity and the urban development strategy, city sign can, for one thing, upgrade the reputation of the city, create city brand, improve the communication between cities in trade and cultural tourism and show the city image, for another, improve the sense of belonging and honor of the urban people, then can improve the whole quality of the city people. It will have a positive significance in promoting urban development and city marketing.

\section{The Development Status of City Sign Design IN OUR COUNTRY}

Chinese urbanization has stepped into the rapid development period in 2000. With the development of economic globalization and the planning and competitive demand meet to urban development in the future, cities are facing the impact of the urbanization wave. Many cities often pay more attention to economic factors but neglect the importance of city sign design which can broadcast the city image. Even in broadcasting city image, we often use the typical city buildings, landscapes, monuments, sculptures directly but never form a unified standard of symbolic visual symbol. Thus, it cannot make the public have a bright impression on the city which causes the absence of many cities' images.

Of course, there are still some successful examples. Hong Kong introduced its city sign "Flying Dragon" on "Fortune Global Forum" in 2001 in order to build the city image of "Asian world city", and then updated the logo in 2010. The extended blue ribbons and green ribbons of the dragon represent the blue sky and green space and the sustainable

Manuscript received March 11, 2012; revised April 12, 2012.

The authors are with School of Urban Design, Wuhan University, Wuhan 430072, China development environment of the city. The red ribbons delineate the mountain ridge of Lion Rock which indicates the competitive spirit - I can do it — of the Hong Kong citizen. Sanya is a famous tropical coastal international city in our country. It identified its city sign in 2010 . The overall shape of the logo takes examples from the expressional gimmick of Chinese calligraphy. It is brief and natural and full of oriental cultural characteristics, thus it is easy for people to remember. This sign design based on the concept of "Feng Wu Tian Ya", stressing the "phoenix" culture, highlighting the core tropical seashore holiday resources such as high quality gulfs and sand beaches. The logo used the gorgeous rainbow gradient color and reflected the natural structure form of the coastal city, so it could let person associate to the sun, the sand, the waves, the coconut trees, clean air and many other unique natural sceneries of the tropical seashore holiday heaven.

\section{The EFFECT OF Establishment OF THE City Sign For CONSTRUCTING CITY BRAND}

City sign is a core factor of city features condensing into visual image symbols and the communication of city brand. The establishment of city brand will play a positive role in improving city image, strengthening urban characteristics, inheriting the city culture, promoting the communication and cooperation between cities, boosting the city economic growth and driving the city tourism development.

\section{A. Improving City Image}

City sign is the external symbol of the city visual image. Through mass media the information of visual symbols will be easier to transfer to the audience. Then the city sign will set up a good image of the cultural connotation, ecological environment and social atmosphere of the city at the same time.

\section{B. Strengthening Urban Characteristics}

City sign was designed by extracting the concrete or abstract elements like representative or symbolic landscape architectures, natural geographical environment, legendary stories and city spirit. And the urban characteristic, connotation and temperament were strengthened by the graphics.

\section{Inheriting the City Culture}

Culture existed not only as a kind of knowledge, a belief system and a way of life, but also as a kind of cultural strength. In the contemporary society, culture has rather become a strategic resource of economic and social development. Urban culture is an important content to reflect the urban development continuation and city sign is an externalization embodiment in visual symbol of the city culture. Mang cultural relics_ such as the pyramids of 
Egypt, Vienna music, Nanjing Qinhuai river and the six dynasties — help the city reveal more historical flavor and charm. They are tangible or intangible cultural assets of the city. In the city sign design, we can extract the cultural quintessence and then apply to graphic symbol design. At the same time, the city sign also pushes the development of urban culture. Along with the spread of the application of the logo, urban culture will get inheritance and development and become the city cultural capital.

\section{Promoting the Communication and Cooperation Between Cities}

The communication of modern economic and culture between cities have become increasingly frequent, any urban area cannot break away from the global environment and existent independently. City sign system can deliver the urban culture through the visual graphics directly and effectively.

\section{E. Boosting the City Economic Growth}

Logo itself has a brand publicity function. With the arrival of the vision era, commodity logo directly bring economic benefit to the goods. A city sets up the city brand through the wonderful logo image system and perfect advertise approaches. All these will promote the economic development.

\section{F. Driving the city Tourism Development}

The development of tourism in a city has become a big industry which drives the economic development . At present, many cities which treat their tourism as the main economic industry define the city sign as the city tourism logo to reflect urban characteristics.Carrying the representative scenic spots or landscapes through visual processing, making it become the visual core elements in city brand image, advertising the city tourism resources in the process of city image promotion, All these would promote the development of tourism in the city.

\section{The EXPREssion of CUltural Elements IN City Sign DESIGN}

Urban culture is the soul of a city. If you think the cities all around the world have tremendous differences, the fundamental one must be the cultural difference. The city image emphasizes the individual character of urban culture elements in a sense. In the age of " thousand cities have one homogeneous style ", develop and use of city culture resources become the success factors in city differentiation competition. The cultural personality of a city is the reflection of national differences, historical differences, traditional differences and religious differences between cities. Integrating the urban culture into sign design, transferring the specific information and shaping their own brand personality. All these would make people clearly grasp the differentiation and then get perception identity.

\section{A. Cultural Attributes of City Sign Graphic}

Many cities have their typical historical sites, landscape architectures and natural landscape features. Their logos often appear in the form of city characteristics and cultural connotation graphics. Because of the variety and complexity of the city contents, the city sign can depend on the key points of the city development, personality characteristics, familiarity of the people and so on, extracting the concrete or abstract elements which can reveal the city connotation and the character from the city environment, combining the contents which modern urban development needs and the temperament the city shaped to deal with artistically.

City sign design can be relatively complex to highlight the combination of history and reality, tradition and modern. The mind of Jinan's city sign comes from the characteristic elements including Spouting Spring, lotus, willow and birds. Above the logo graphic is a yamagata terrain, it also implicated an Epicureans bird image. The Epicureans bird was ancient totem worship in the old city. It typically revealed the characteristics of the regional culture and symbolized good fortune. The lower part of the graphic highlight the Bao Tu Quan image, strengthen the visual impression, reveal the natural landscape and human element of the city, make the graphic lively and vividly, reflect the harmonious natural ecology of the city. The other auxiliary sign design also follows the above design concept and expression technique; highlight the ecological landscape which is harmoniously coexistence such as willow, lotus, spring water and so on.

\section{B. Cultural Connotation of City Sign Character}

Character is a symbol which directly transmits language information. The characteristics of the city reflect the recognition and artistic quality through the redesign of characters. Firstly, the category of characters reflect the cultural regional diversity. Secondly, the differences of the cultural development level within large areas will produce a certain effect on the development of the characters. For example, a city with long history and culture and regional features would be different from a modern city in application of the character design in the display of the external image. The former can use calligraphy form or stroke design which can represent city visual imagery to show the deep cultural heritage of the city. Hangzhou identified its city sign in 2008. The whole logo graphic is like a ship. The Chinese character "hang" means a boat in ancient China, so the logo reflects the historical and cultural background of the city and symbolizes the aggressive and positive spirits. The strokes integrate the expression in form of warped corner and arch which are the landmark buildings in Jiangnan. They present the Chinese traditional culture and its' regional characteristics. The right part of the graphic indicates the famous scenery spot image- Three Pools Mirroring The Moon-in hangzhou, all these reveal the unique charm and archaic rhyme of the ancient city without reservation. The latter may redesign the characters with concise and contemporary gimmick to show the development direction and the vigorous image of the city. At the same time, we can use typical regional words combining with graphics to design the city sign in national regions such as Ningxia, Guangxi, Xinjiang, Tibet and son on.

Character design must ensure that the audiences have a clear recognition of the design. Identity, diversity, nationality and internationality are the most important principles we 
must follow in the process of city sign design.

\section{Cultural Characteristics of City Sign Color}

City itself is a collection of colors. People in cities are always feeling the charm of color. The city color was also influenced by history, geographical environment, humanistic landscape features and traditional political culture to present regional cultural characteristics as well. Beijing is a traditional capital city in history, golden yellow and vermilion are the typical colors of this city. Color in the ancient society has a clear hierarchy. Vermilion,yellow, red and purple are monopolized by monarchy and nobility, which ordinary people had no access to use them. These symbolic colors were applied into emblem design of Beijing Olympic Games in 2008 to show the Chinese image in front of the world.

Different people have different color preferences, so we must get the recognition of the citizen in the color application of city sign design. We should make good investigation in the design process and synthesize the representative landscape architecture, historical and cultural sites, natural landscapes and folk culture to extract the city sign color, to make the general public recognized our design to the fullest extent.

\section{The Communication and Promotion of City Sign DESIGN}

City sign is an important intangible asset of a city .Therefore, in order to improve the recognition and reputation of the public and the overall brand image of the city, the city will need to apply their own unique city sign to different communication means and dissemination ways.

The film and television advertisement is the most often used way in communicating city image and broadcasting its city sign design. Through this way, the city can show its unique city sign comprehensively and give audience an intuitive impression. In the 2008 Olympic Games in Beijing, a famous song - welcome to Beijing - included almost all the famous landmarks and various humanistic spirits of Beijing. At the same time, its city sign was broadcast through newspapers, magazines, presses and other comprehensive means to achieve maximum transmission efficiency.

City sign itself is a concept of multiple and rich connotation, a single media in constructing and shaping a city character may not be so comprehensive. So in order to further enrich the image of the city in media, we must pay attention to using multimedia to show the city sign from different levels and forms. Shanghai combined the characteristic and the superiority of the World Expo actively, comprehensively used many traditional platforms like the television, radio, newspapers, magazines and so on to spread its city sign, in the use of new media, Shanghai applied three - screen fusion technology and broadcast city symbols in a variety of channels and platforms.

In addition, with the spread of the Internet, the way of mass interpersonal communication also expanded up. In the past few years, with the rise of the network, the use of the interpersonal communication platform which is cheap and fast will make the city sign spread more quickly.

\section{CONCLUSION}

All the cities would like to spare no effort to give people a clear memory and impression about themselves. In this process, the unique cultural element is the most important part to realize the city sign spread extensively. We should pay more attention to the future direction of the city and make sure the logo and its extensive application system can adapt to the development of the age.

\section{REFERENCES}

[1] P. Y. Zhao, Introduction to design, Beijing:Higher Education Press, 2006.

[2] H. Y. Zhang, The city image and the city cultural capital, Nanjing:Southeastern University Press, 2002.

[3] H. L. Guo, Enterprise and brand image design, Beijing:Chinese Architecture Industry Press, 2005.

[4] L. X. Chen, Urban culture and city spirit, Nanjing:Southeastern University Press, 2002.

[5] Z. M. Zhuang, Tourism economic and cultural research, Shanghai: Lixin Accountant Press, 2005. 